\title{
INHIBITION OF ONCOSTATIN M IN OSTEOARTHRITIC SYNOVIAL FLUID ENHANCES GAG PRODUCTION IN OSTEOARTHRITIC CARTILAGE REPAIR
}

\author{
Michiel Beekhuizen ${ }^{1}$, Gerjo J. V. M. van Osch ${ }^{2}$, Arjan G. J. Bot ${ }^{1}$, Myrthe C. L. Hoekstra ${ }^{1}$, Daniel B. F. Saris ${ }^{1,3}$, \\ Wouter J. A. Dhert ${ }^{1,4}$ and Laura B. Creemers ${ }^{1, *}$
}

\author{
${ }^{1}$ Dept. of Orthopaedics, University Medical Centre Utrecht, Utrecht, The Netherlands \\ ${ }^{2}$ Dept. of Orthopaedics and Dept. of Otorhinolaryngology, Erasmus MC, University Medical Centre, Rotterdam, The \\ Netherlands \\ ${ }^{3}$ University of Twente, MIRA Institute Tissue Reconstruction, Enschede, The Netherlands \\ ${ }^{4}$ Faculty of Veterinary Medicine, Utrecht University, Utrecht, The Netherlands
}

\begin{abstract}
Mediators in the synovial fluid are thought to play a major role in osteoarthritic cartilage turnover. The purpose of the current study was to investigate the role of oncostatin $M$ (OSM) in osteoarthritis (OA) by evaluating the presence of the cytokine and its receptors in the OA joint and interfering with its activity in synovial fluid co-cultured with cartilage explants. OSM levels were increased in the synovial fluid of osteoarthritic patients compared to healthy donors. Immunohistochemistry confirmed the presence of both the leukaemia inhibitory factor (LIF) and OSM receptors for OSM throughout the whole depth of osteoarthritic cartilage and synovial tissue, whereas in healthy cartilage their presence seemed more restricted to the superficial zone. Blocking OSM activity, using an activity inhibiting antibody, in $25 \%$ osteoarthritic synovial fluid added to OA cartilage explant cultures increased glycosaminoglycan (GAG) content from $18.6 \mathrm{mg} / \mathrm{g}$ to $24.3 \mathrm{mg} / \mathrm{g}(P<0.03)$ and total production from $7.0 \mathrm{mg} / \mathrm{g}$ to $11.9 \mathrm{mg} / \mathrm{g}(P<0.003)$. However, OSM exogenously added to cartilage explant cultures reflecting low and high concentrations in the synovial fluid ( 5 and $50 \mathrm{pg} / \mathrm{mL}$ ) did not affect cartilage matrix turnover, suggesting that factors present in the synovial fluid act in concert with OSM to inhibit GAG production. The current study indicates the potential to enhance cartilage repair in osteoarthritis by modulating the joint environment by interfering with OSM activity.
\end{abstract}

Keywords: Oncostatin M; cartilage; osteoarthritis.

\author{
*Address for correspondence: \\ L. B. Creemers, PhD \\ Department of Orthopaedics \\ University Medical Centre Utrecht \\ Heidelberglaan 100 \\ PO Box 85090 \\ 3508AB Utrecht \\ The Netherlands
}

Telephone Number: +31887550293

FAX Number: +31302510638

E-mail: 1.b.creemers@umcutrecht.nl

\section{Introduction}

One of the key processes in osteoarthritis (OA) is loss of the articular cartilage extracellular matrix due to a shift of the balance between production and degradation. Increased synthetic activity is evident by clonal expansion of resident chondrocytes and increased intensity of the territorial matrix surrounding them. However, this cannot compensate for the generalised loss of proteoglycans in the extraterritorial matrix, leading to a net loss of cartilage matrix (Martel-Pelletier et al., 2008). Soluble factors secreted from cartilage, synovial tissue and bone are known to play a role in the turnover of cartilage matrix, and many have been shown to both increase cartilage degeneration and inhibit the production of the extracellular matrix, which has been documented most extensively for interleukin-1 (IL-1) and tumour necrosis factor- $\alpha$ (TNF $\alpha)$ (Fernandes et al., 2002; Goldring and Marcu, 2009; Goldring and Goldring, 2004; MartelPelletier et al., 1999). Another soluble factor that may be important in affecting cartilage matrix integrity in OA is the pro-inflammatory cytokine oncostatin M (OSM). OSM, a cytokine from the interleukin-6 (IL-6) family, is secreted by osteoarthritic synovial tissue (Beekhuizen et al., 2011) and is found in rheumatoid synovial fluid (Hui et al., 1997). OSM is associated with multiple processes in the body, e.g. haematopoiesis, neural and liver development and cell proliferation (Miyajima et al., 2000; Tanaka et al., 2003; Tanaka and Umesaki, 2003) and in rheumatoid arthritis (RA), OSM is associated with bone erosion, synovial inflammation and fibrosis, and cartilage degeneration (Sims and Walsh, 2010; Walker et al., 2010). The potential of OSM to degenerate cartilage and induce catabolic processes in chondrocytes was shown in different studies (Barksby et al., 2006; Durigova et al., 2011), although nothing is known about its effect on cartilage synthesis. In addition, OSM is known to synergise with catabolic cytokines such as IL-1 and TNF $\alpha$ in the induction of cartilage degeneration in vitro (Barksby et al., 2006; Catterall et al., 2001; Gilbert et al., 2012; Hui et al., 2001; Hui et al., 2003). However, most pro-inflammatory cytokines, including OSM, have been demonstrated only at low levels in osteoarthritic synovial fluid (Hui et al., 1997; Manicourt et al., 2000; Okamoto et al., 1997; Rutgers et al., 2009), and it is not clear whether such interactions are relevant in OA-associated cartilage degeneration in vivo. Moreover, therapies targeting IL-1 and TNF $\alpha$ were shown to be ineffective in inhibiting 
osteoarthritic cartilage loss, in contrast to their application in rheumatoid arthritis.

OSM signals through two different receptor complexes, the GP130/LIFR $\beta$ (LIFR) or the GP130/OSMR $\beta$ (OSMR) complex (Gearing et al., 1992; Mosley et al., 1996; Thoma et al., 1994). The OSMR was demonstrated in a chondrocyte cell line and in synovial fibroblasts. In addition, OSM signalling is mediated through the protein kinase $\mathrm{R}$ signalling pathway in bovine chondrocytes (Gilbert et al., 2012). Although both receptors for OSM have been shown in multiple tissues, e.g. liver and prostate with different expression in healthy and pathologic conditions (Royuela et al., 2004; Znoyko et al., 2005), the presence of the different receptors for OSM has not been studied in healthy or in osteoarthritic cartilage tissue in vivo (Rowan et al., 2001).

The purpose of this study was to elucidate the role of OSM in OA and more specifically the effect of inhibiting OSM on cartilage integrity in OA. To this end, the levels of OSM in the synovial fluid of osteoarthritic patients were compared to healthy subjects, and the presence of receptors for OSM was evaluated in healthy and osteoarthritic joint tissue. Furthermore, the role of OSM in cartilage repair was studied by culture of OA cartilage explants with OA synovial fluid in the presence or absence of a blocking antibody against OSM. Finally, to determine whether OSM could directly affect cartilage repair, the effect of recombinant OSM on cartilage explants at concentrations found in OA synovial fluid was studied.

\section{Materials and Methods}

\section{Harvesting of cartilage, synovial tissue and synovial fluid}

Osteoarthritic cartilage was collected under sterile conditions from patients undergoing total knee arthroplasty for OA. Cartilage explants were harvested from the femoral condyles, cut into square pieces of approximately 1 x $1 \mathrm{~mm}$ and the wet weight was determined so glycosaminoglycan (GAG) release, content and production could be corrected for cartilage weight (Mastbergen et al., 2005). No difference was made between damaged or more intact cartilage, for histology, tissue analysis nor explant cultures. Only the almost completely denuded bone areas were not used. From each donor, 6 cartilage explants were fixed immediately in $4 \%$ formaldehyde for histological evaluation and 6 were wet weighted and stored at $-20{ }^{\circ} \mathrm{C}$ for biochemical analysis at $\mathrm{t}=0$. The rest of the explants were used for culturing or cell isolation.

Osteoarthritic synovial fluid and synovial tissue was obtained during total knee arthroplasty, healthy synovial fluid and tissue were collected from post mortem donors within $24 \mathrm{~h}$ after death, only if the knee cartilage was macroscopically healthy. The synovial tissue was immediately fixed in $4 \%$ formaldehyde for immunohistochemical analysis. Synovial fluid was stored at $-80{ }^{\circ} \mathrm{C}$.

To obtain OA chondrocytes, articular cartilage was cut and digested in collagenase $0.15 \%$ (Worthington, Lakewood, NJ, USA) overnight at $37^{\circ} \mathrm{C}$. Subsequently, the chondrocytes were seeded in a monolayer at a cell density of 5000 cells $/ \mathrm{cm}^{2}$ and cultured in expansion medium containing Dulbecco's Modified Eagle Medium (DMEM), $10 \%$ foetal bovine serum (FBS), $1 \%$ penicillin/ streptomycin (pen/strep) and $10 \mathrm{ng} / \mathrm{mL}$ basic fibroblast growth factor (bFGF; R\&D Systems, Minneapolis, MN, USA). Chondrocytes were cultured until passage 2 . Anonymous use of redundant tissue for research purposes is part of the standard treatment agreement with patients in our university hospital and according to the national guidelines 'code of conduct for the proper secondary use of human tissue' (van Diest, 2002).

\section{Multiplex ELISA}

The presence of OSM in synovial fluid was determined using multiplex ELISA, as part of a multiplex ELISA for several cytokines, as previous described (Beekhuizen et al., 2011). Validation of the Multiplex ELISA was previously done by de Jager et al., showing excellent sensitivity and specificity (de Jager et al., 2005; de Jager et al., 2003). Synovial fluid was pre-treated with hyaluronidase for 15 min at $37^{\circ} \mathrm{C}$. Samples were spun down in a X-column (Costar 8169; Corning Inc, Corning, NY, USA) and dissolved in $0.1375 \%$ high performance ELISA buffer (HPE)-Tween-20. The pre-treated synovial fluid was incubated with the coupled beads. After incubation with the biotinylated antibodies, samples were incubated with streptavidin-phycoerythrin (PE). The samples were measured and analysed using the Bio-Plex suspension system (Bio-Rad Laboratories, Hercules, CA, USA). The concentration of OSM in the synovial fluid was calculated using the standard curve and is expressed as $\mathrm{pg} / \mathrm{mL}$.

\section{(Immuno)histochemistry}

For (immuno)histochemistry, the cartilage and synovial tissue explants were fixed overnight in $4 \%$ formaldehyde, embedded in paraffin and cut into $5 \mu \mathrm{m}$ sections. To evaluate the cartilage degeneration grade (Pritzker et al., 2006), a safranin-O and fast-green staining was used (Rosenberg, 1971). For LIFR staining (sc-659, C-19; Santa Cruz Biotechnologies, Santa Cruz, CA, USA), sections were incubated with polyclonal anti-rabbit LIFR $\beta$ (both cartilage and synovial tissue; concentration $0.67 \mu \mathrm{g} /$ $\mathrm{mL}$ ) for $1 \mathrm{~h}$ at room temperature (Royuela et al., 2004; Znoyko et al., 2005). The sections were incubated with anti-rabbit-horseradish peroxidase (HRP) $(1.25 \mu \mathrm{g} / \mathrm{mL}$; Dako, Glostrup, Denmark). Sections were developed by incubations with 3,3'diaminobenzidine (DAB) for 5 min. For OSMR staining, sections were incubated with polyclonal anti-goat OSMR $\beta$ (sc-8496, C-20; SantaCruz; for cartilage sections at $2.0 \mu \mathrm{g} / \mathrm{mL}$ and synovial tissue at $4.0 \mu \mathrm{g} / \mathrm{mL}$ ) overnight. Sections were incubated with antigoat-HRP $(2.5 \mu \mathrm{g} / \mathrm{mL}$, Dako) for $1 \mathrm{~h}$. Finally, sections were developed by incubation with DAB. For the negative controls, adjacent sections of both healthy and osteoarthritic cartilage and synovial tissue were incubated with an isotype anti-rabbit IgG (Dako) for the LIFR or isotype anti-goat IgG (Santa Cruz Biotechnologies) for OSMR. As a positive control, human thymus sections were used.

To quantify the LIFR and OSMR staining, the percentage of positive cells in both cartilage and synovial 
tissue sections was determined using semi-automatic software (Leica Microsystems, Rijswijk, The Netherlands). The cells were counted with a grid distance of $17.6 \mu \mathrm{m}$. All sections were blinded and at least 100 cells were counted per slide. In total at least 5 healthy and 5 OA donors were used for both cartilage and synovial tissue. For the cartilage explants, only the positive cells in the middle and deep layer were counted, due to the loss of the superficial layer in OA cartilage explants. For synovial tissue, all cells throughout the entire tissue were counted.

\section{Culture of cartilage explants in OA synovial fluid}

To evaluate the effect of OSM present in synovial fluid on cartilage metabolism, the activity of OSM in OA synovial fluid was blocked with an activity-inhibiting antibody. For these experiments the synovial fluid from multiple $( \pm 8) \mathrm{OA}$ donors were pooled to obtain sufficient amounts of synovial fluid for a total culture period of $14 \mathrm{~d}$. In total 3 different pooled synovial fluids were used, at OSM concentrations between 25 and $40 \mathrm{pg} / \mathrm{mL}$. The pooled synovial fluid was aliquoted and stored at $-80^{\circ} \mathrm{C}$ until use. Cartilage explants from 5 different donors ( $n=6$ per donor/per condition) were cultured in the presence or absence of $25 \%$ pooled OA synovial fluid, at a final OSM concentration of 6.25 or $11.25 \mathrm{pg} / \mathrm{mL}$ (25\% OA synovial fluid dissolved in medium), in DMEM (Gibco BRL Life Technologies, Darmstadt, Germany) containing penicillin and streptomycin (Gibco), ascorbate-2-phosphate (Sigma-Aldrich, St Louis, MO, USA), Insulin Transferrin Selenium-X (ITS-X) (Gibco) and $50 \mu \mathrm{g} / \mathrm{mL}$ L-proline (Sigma) for $14 \mathrm{~d}$. To block the effect of OSM, an activity-inhibiting antibody against OSM was used at a concentration of $10 \mu \mathrm{g} / \mathrm{mL}$ (MAB295; R\&D, Minneapolis, MN, USA). Isotype IgG antibody (MAB002; R\&D) and cultures with anti-OSM antibody only served as controls. The culture medium was renewed 3 times per week. For each medium change, fresh synovial fluid (25\%) and anti-OSM or isotype antibody was added to the culture medium. The supernatant was stored at $-80^{\circ} \mathrm{C}$ for further analysis. After $14 \mathrm{~d}$ of culture, one explant was fixed for histochemical analysis. The rest of the explants were stored at $-20{ }^{\circ} \mathrm{C}$ for biochemical analysis.

\section{Effect of OSM inhibition on PGE2 production by OSM stimulated OA chondrocytes}

To assess whether the anti-OSM antibody was effectively blocking OSM activity, OA chondrocytes were cultured in the presence or absence of $2 \mathrm{ng} / \mathrm{mL}$ recombinant OSM, or $10 \mu \mathrm{g} / \mathrm{mL}$ OSM activity-inhibiting antibody (anti-OSM). As a control, unstimulated cells and an isotype IgG were used. The OA chondrocytes were seeded in a density of 42,000 cells per well for a total culture period of $3 \mathrm{~d}$. After $3 \mathrm{~d}$, the conditioned medium was stored. The inhibiting effect of anti-OSM was determined using a prostaglandin E2 (PGE2) ELISA. In total 1 OA donor was used with $n=4$ per condition.

\section{PGE2 analysis}

PGE2 concentration in the conditioned medium of OSM stimulated $\mathrm{OA}$ chondrocytes was determined using a competitive PGE2 ELISA (ENZO Life Sciences, Antwerpen, Belgium), according to the manufacturer's protocol.

\section{Culture of cartilage explants in the presence of recombinant OSM}

OA cartilage explants from 4 different donors $(n=6$ per donor/per condition) were cultured for $14 \mathrm{~d}$ in the presence or absence of recombinant OSM (295-OM; R\&D) at 5 and $50 \mathrm{pg} / \mathrm{mL}$, representing the lowest and the average concentration of OSM found in OA synovial fluid. As a positive control a concentration of $10 \mathrm{ng} / \mathrm{mL}$, previously shown to have an effect on cartilage metabolism (Durigova et al., 2008a; Durigova et al., 2008b), was also included. Culture medium was renewed 3 times a week and stored at $-80^{\circ} \mathrm{C}$ for further analysis. One explant was fixed for further histochemical analysis. The remaining explants $(\mathrm{n}=5)$ were stored at $-20{ }^{\circ} \mathrm{C}$ for biochemical analysis.

\section{Biochemistry}

GAG release and total GAG content was quantified using the dimethylmethylene-blue (DMMB) spectrophotometric analysis described by Farndale et al. (1986). Cartilage explants were digested in $400 \mu \mathrm{L} 2 \%$ papain (Sigma) in $50 \mathrm{mM}$ phosphate buffer, $2 \mathrm{mM} \mathrm{N}$-acetylcysteine, and $2 \mathrm{mM} \mathrm{Na}_{2}$-EDTA (pH 6.5) at $60{ }^{\circ} \mathrm{C}$ overnight. Two hundred $\mu \mathrm{L}$ of DMMB solution and $100 \mu \mathrm{L}$ of medium sample or papain digest were mixed and absorbance read at $540 \mathrm{~nm}$ and $595 \mathrm{~nm}$ using a spectophotometer (BioRad Laboratories). As reference, chondroitin sulphate C (Sigma) was used. Calculation of GAG production was performed using the following formula:

Table 1. Results of LIFR and OSMR staining in osteoarthritic and healthy cartilage and synovial tissue.

\begin{tabular}{|l|c|c|c|}
\hline & Healthy (\% \pm SD) & Osteoarthritic (\% \pm SD) & $P$ value \\
\hline Cartilage & & & \\
\hline LIFR & $73.0 \pm 10.4$ & $72.3 \pm 21.9$ & 1.00 \\
\hline OSMR & $19.4 \pm 16.5$ & $24.4 \pm 16.8$ & 0.73 \\
\hline & & & \\
\hline Synovial tissue & & & \\
\hline LIFR & $71.2 \pm 4.3$ & $86.3 \pm 9.0$ & $* 0.04$ \\
\hline OSMR & $0 \pm 0$ & $10.3 \pm 12.9$ & $* 0.04$ \\
\hline
\end{tabular}

Per condition 5 samples were scored using semi-automatic software. At least 100 cells were counted per section. Data is given in $\% \pm \mathrm{SD}$ of positive cells. 
GAG $=(\mathrm{GAG}$ $-\mathrm{GAG}_{\mathrm{c}}$ ) $+\mathrm{GAG}$

given in $\mathrm{mg} \mathrm{GAG} / \mathrm{g}$ cartilage.

\section{Statistical analysis}

Data are expressed as mean \pm SD. SPSS 16.0 software (SPSS Inc. Chicago, IL, USA) was used for the statistical analysis. The data was tested for normality and Gaussian distribution. A Student's $t$-test was used to assess difference between the healthy and osteoarthritic synovial fluid samples. Univariate analysis of variance (ANOVA), with a randomised block design and a post-hoc Bonferroni was used to assess differences in the glycosaminoglycan parameters. Differences with a $P$-value less than 0.05 were considered statistically significant. Differences in the percentage of receptor-positive cells in cartilage and synovial tissue scored after immunohistochemistry were evaluated by a Mann-Whitney U test.

\section{Results}

\section{Presence of OSM in OA synovial fluid}

In the OA synovial fluid samples OSM was detected in 10 of the 32 samples (range $0-570 \mathrm{pg} / \mathrm{mL}$; mean $39 \mathrm{pg} /$ $\mathrm{mL}$ ), whereas in the healthy samples only one of the 23 samples contained OSM (range $0-25 \mathrm{pg} / \mathrm{mL}$; mean $1 \mathrm{pg}$ / $\mathrm{mL} ; P<0.001$ ) (Fig. 1).

\section{Presence of receptors for OSM in joint tissue}

The LIFR was present throughout the entire cartilage depth in both osteoarthritic and healthy cartilage (Fig. 2). In healthy cartilage, the OSMR was mainly expressed in chondrocytes in the superficial layer and some chondrocytes in the middle and deep layer. However, in osteoarthritic cartilage, positive chondrocytes were found throughout the entire cartilage (Fig. 3). As the superficial layer in OA cartilage was lost, only the middle and deep zones of healthy and OA tissues were quantified for the presence of LIF and OSM receptor-positive cells. No statistically significant difference between healthy and OA cartilage for LIFR nor OSMR staining was found (Table 1).

Synovial tissue of both healthy and osteoarthritic joints expressed the LIFR (Fig. 4), with positive cells mainly expressed in the synovial tissue lining. The expression of LIFR in OA synovial tissue was slightly higher compared with healthy synovial tissue $(P<0.04$; Table 1). Furthermore, the OSMR was not expressed in any of the healthy synovial tissue donors (Fig. 4 and Table 1), whereas in the osteoarthritic synovial tissue multiple cells in the synovial lining expressed the OSMR $(P<0.04$; Fig. 4 and Table 1).

Effect of blocking OSM in synovial fluid on cartilage To study the role of OSM in osteoarthritic cartilage degeneration, OA cartilage explants were cultured in the presence of OA synovial fluid (the OSM concentration in the pooled synovial fluids ranged between 30 and $40 \mathrm{pg} /$ $\mathrm{mL}$; data not shown), in the presence or absence of an activity-inhibiting antibody against OSM (anti-OSM). Although addition of OA synovial fluid to cartilage

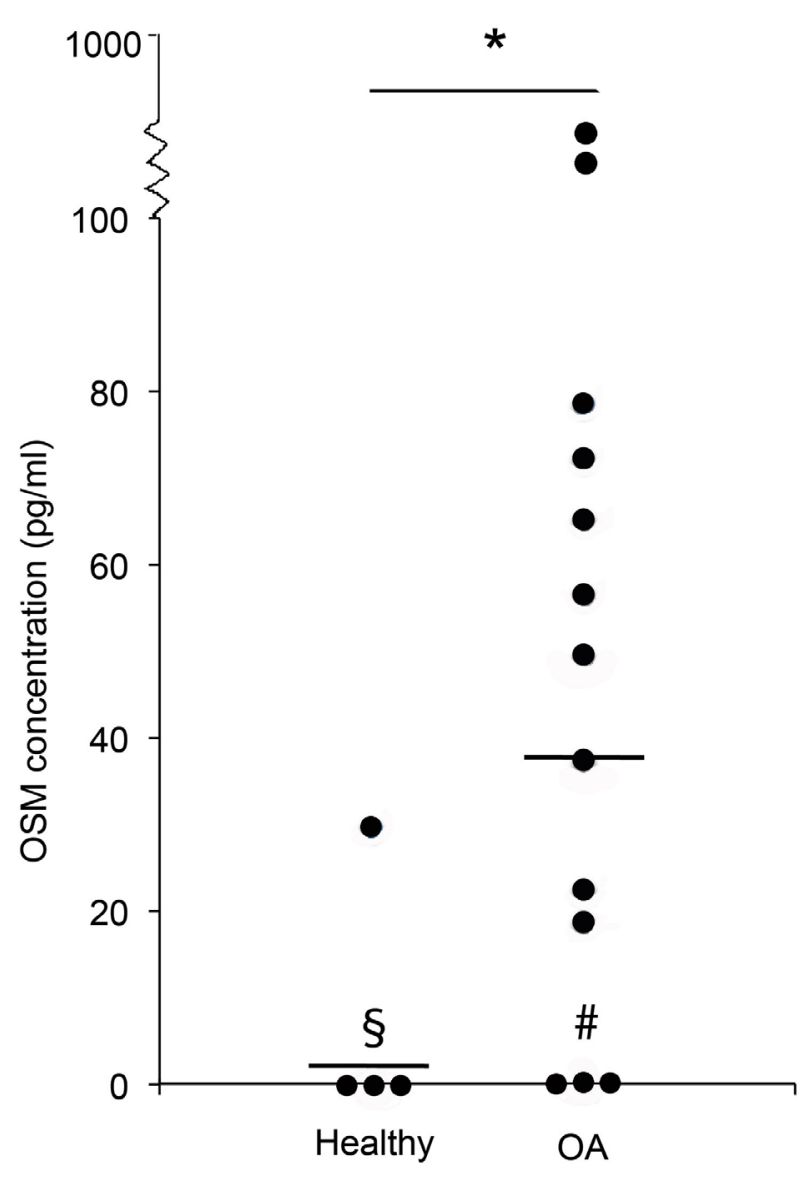

Fig. 1. OSM concentration in healthy $(n=24)$ and osteoarthritic $(n=32)$ synovial fluid samples. In healthy synovial fluid OSM was detected in only one sample $(1.5 \pm 6.8 \mathrm{pg} / \mathrm{mL})$. In osteoarthritic synovial fluids OSM was detected in 10 out of 32 samples $(39.7 \pm 108.0 \mathrm{pg} /$ $\mathrm{mL} ; * P<0.001) . \S=24$ samples, $\#=22$ samples.

explants for $14 \mathrm{~d}$ did not affect GAG content, release or production in cartilage explants (Fig. 5), blocking OSM in OA synovial fluid increased GAG content from $18.6 \mathrm{mg} / \mathrm{g}$ to $24.3 \mathrm{mg} / \mathrm{g}(P<0.03)$ and production from $7.0 \mathrm{mg} / \mathrm{g}$ to $11.9 \mathrm{mg} / \mathrm{g}(P<0.003)$ in cartilage explants (Fig. 5a,c). Blocking OSM in synovial fluid did not have an effect on GAG release (Fig. 5b). Anti-OSM did not affect any of the turnover parameters in cartilage explants in the absence of synovial fluid. The effectiveness of the antibody was shown in OSM-stimulated OA chondrocytes, where the effect of recombinant OSM on PGE2 production was completely abrogated by the anti-OSM antibody but not by the isotype control (Fig. 5d; $P<0.001$ ). There was a basal production of PGE2 by the OA chondrocytes as shown by the unstimulated control.

\section{Effect of recombinant OSM on OA cartilage}

The effect of OSM alone on OA cartilage explants was studied by addition of recombinant OSM to OA cartilage explants. Only at a supraphysiological concentration of $10 \mathrm{ng} / \mathrm{mL}$, but not at 5 or $50 \mathrm{pg} / \mathrm{mL}, \mathrm{GAG}$ content decreased and GAG release increased (Fig. 6a/b; $P<0.05$ and $P<0.001)$. No effect on total GAG production was noted irrespective of the concentration used (Fig. 6c). 


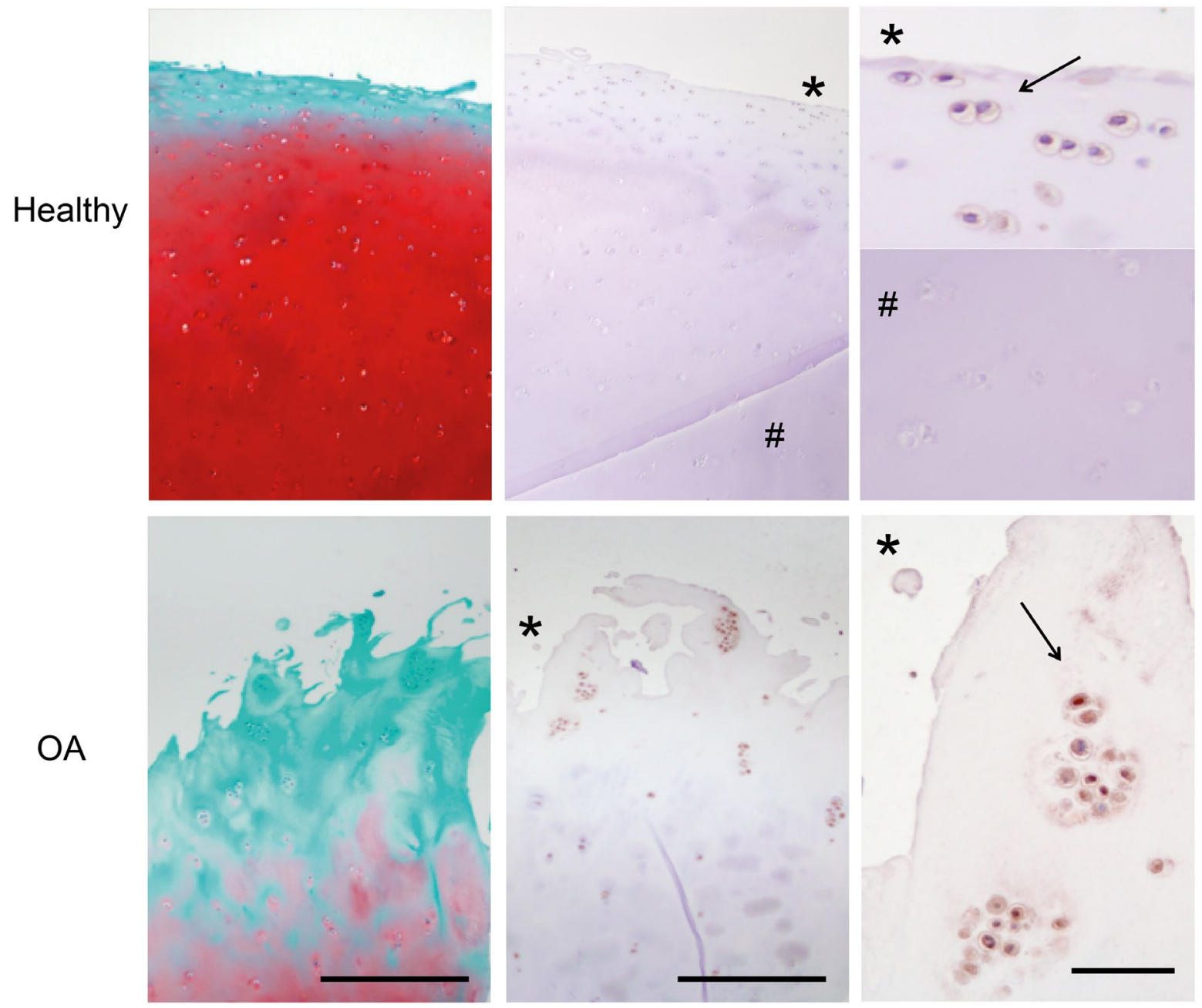

Fig. 2. Immunohistochemistry for LIFR in healthy (upper panels) and osteoarthritic cartilage (lower panels). LIFR is present in osteoarthritic cartilage throughout the entire cartilage (middle and right lower panels). In the healthy cartilage, only some cells in the superficial layer showed positive staining (middle and right upper panels). The left panels show the safranin-O staining of the healthy (upper left) and osteoarthritic cartilage (lower left). Positive cells stained brown by DAB and indicated by the arrow; scale bar represents $500 \mu \mathrm{m}$, or $40 \mu \mathrm{m}$ (magnified right panels).

\section{Discussion}

The current study showed increased levels of OSM in osteoarthritic synovial fluid and expression of both receptors for OSM in cartilage and synovial tissue. Although the receptors were found both in healthy and OA joint tissue, their expression seemed to be more widespread in OA tissue. Addition of OA synovial fluid to cartilage explant cultures did not affect matrix turnover. However, when OSM was blocked in OA synovial fluid, cartilage repair was clearly enhanced. In contrast, recombinant OSM added to cartilage explants at the concentrations found in OA synovial fluid did not affect chondrocyte metabolism.

The role of OSM in rheumatoid arthritis and joint tissues other than cartilage has been extensively studied (Cawston et al., 1998; Hui et al., 2005; Nowell et al., 2006; Walker et al., 2010). OSM in combination with IL-1 or TNF $\alpha$ induced bone destruction via the RANK/RANKL pathway (Hui et al., 2005). Moreover, OSM triggered angiogenesis and cell migration in synovial tissue (Fearon et al., 2006). These changes are also known to occur in OA in synovial tissue (Felson, 2006). In RA, however, the levels of the pro-inflammatory cytokines IL-1, TNF $\alpha$ and OSM are high, in contrast to OA where almost no IL-1 or $\mathrm{TNF} \alpha$ is present. Possibly, this might cause the different effects of OSM in RA compared to OA.

Receptors for OSM are found in multiple cell types in the joint, such as osteoblasts, synovial fibroblasts and chondrocytes, indicating that OSM could exert an effect on all tissues in the joint. Rowan et al. (2001) showed the presence of GP130/OSMRß complex, but failed to detect the GP130/LIFRß complex, in an immortalised chondrocyte cell line. Other studies showed the presence of the OSMR and LIFR in both osteoblasts (Allan et al., 1990; Walker et al., 2010) and synovial fibroblasts (Nowell et al., 2006). However, OSM receptor expression in healthy and diseased joint tissue has never been reported before, let alone the existence of differences in expression between healthy and diseased tissue. Although OSM receptor expression was not evidently different in cartilage tissue, 


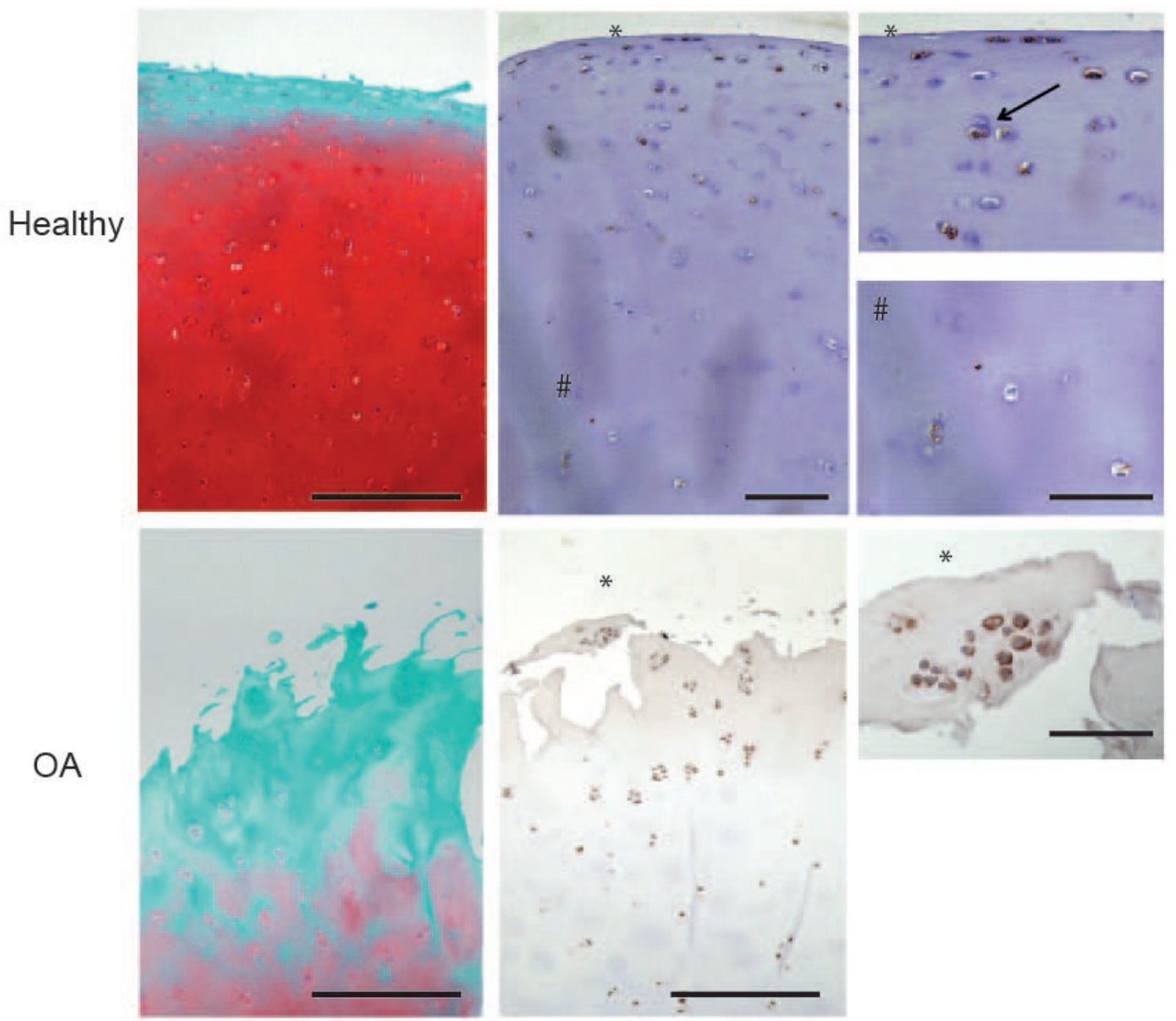

Fig. 3. Immunohistochemistry for OSMR in healthy (upper panels) and osteoarthritic cartilage (lower panels). OSMR is present in osteoarthritic cartilage throughout the entire cartilage (middle and right lower panels). In the healthy cartilage cells in the superficial layer showed positive staining and some cells in the middle/deep layer (middle and right upper panels). The left panels show the safranin-O staining of the healthy (upper left) and osteoarthritic cartilage (lower left). Positive cells stained brown by DAB and indicated by the arrow; scale bar represents $500 \mu \mathrm{m}$, or $40 \mu \mathrm{m}$ (magnified right panels).

in synovial tissue the expression of the receptors for OSM was up-regulated in osteoarthritic samples, in contrast to healthy tissue where almost no cells were positive. This indicates an increased expression of the OSMR in diseased joint tissue, which may further enhance the effects induced by OSM. In addition, the LIFR was upregulated in osteoarthritic synovial tissue.

Studies have showed that gene activation through the LIFR and the OSMR are different. Whereas OSM normally signals through the LIFR and activates JAK/STAT transcriptional activators, OSM can also act via OSMR. However, the OSMR can also activate specific pathways through activation of the MAPK signalling cascade (Halfter et al., 1999; Mosley et al., 1996), suggesting that dependent on receptor expression, different responses, e.g. MMP activity and chondrocyte metabolism, could be generated in osteoarthritis. OSM is the only cytokine from the IL-6 family that can induce cartilage degeneration, albeit at non-physiologically high concentrations (Hui et al., 2000; Hui et al., 2003). This is most likely via the induction of matrix degrading proteases, e.g. MMPs and ADAMTS, which are known to be increased in OSMstimulated cartilage explants or chondrocyte cultures (Durigova et al., 2008a; Durigova et al., 2008b; Durigova et al., 2011; Gilbert et al., 2012). Although the proteases involved downstream of OSM signalling were not further identified in the current study, stimulation of GAG release by the addition of a high concentration of OSM is in line with previous data.

In RA, OSM levels are high and in concert with high concentrations of IL-1 and TNF $\alpha$ known to induce degeneration and GAG release (Manicourt et al., 2000). The use of neutralising OSM antibodies in two different models of murine RA was shown to partially prevent 

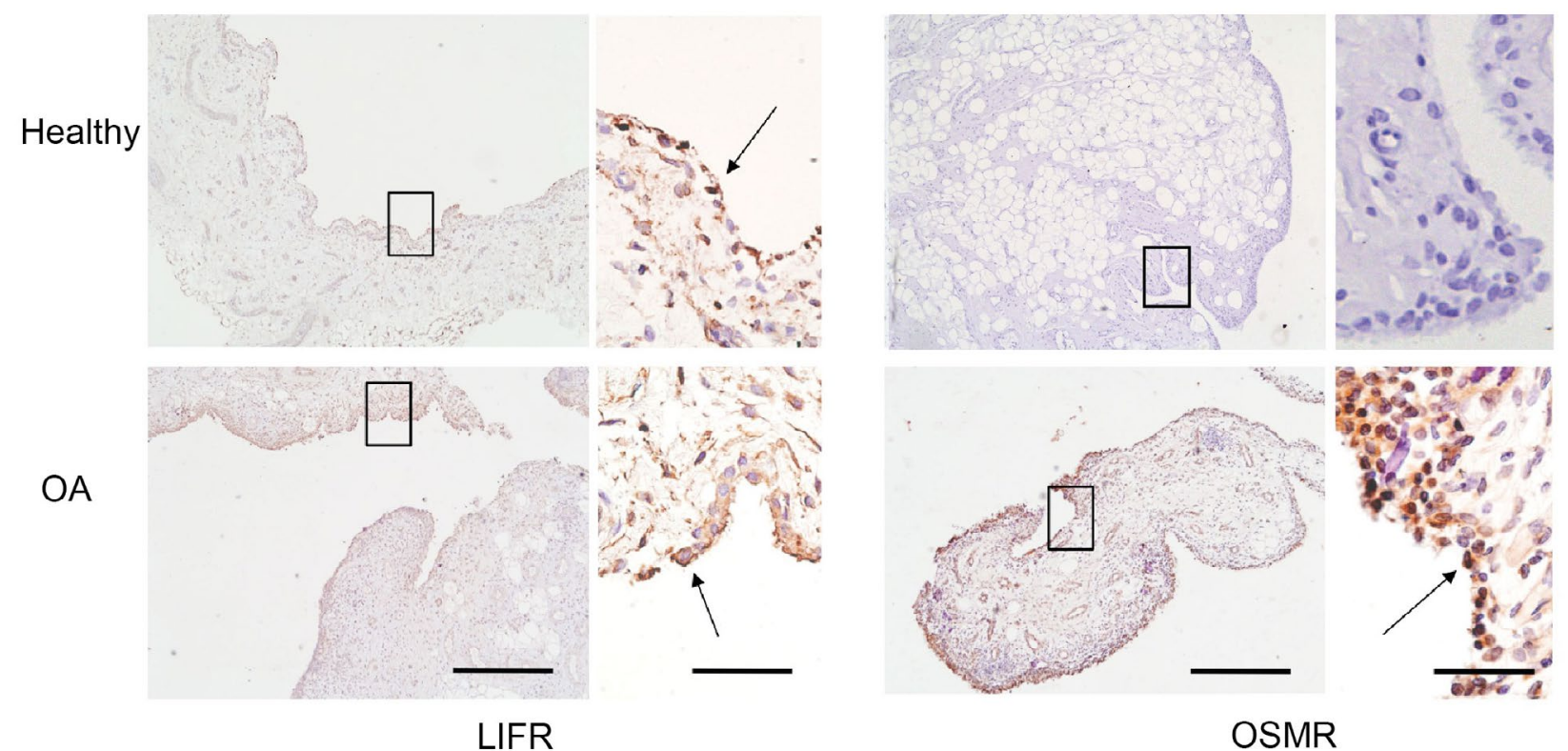

Fig. 4. Immunohistochemistry for LIFR and OSMR in healthy and osteoarthritic synovial tissue. LIFR is present in both healthy and osteoarthritic synovial tissue (left pictures). OSMR was abundantly expressed in osteoarthritic synovial tissue, however not in healthy synovial tissue (right pictures; positive cells stained brown by DAB and indicated by the arrow; scale bar represents $500 \mu \mathrm{m}$, or $20 \mu \mathrm{m}$ in magnified panel).

cartilage destruction (Plater-Zyberk et al., 2001). In addition, blockers of several cytokines binding the GP130 family of receptors, such as IL-6, are currently used in the clinic (Maini et al., 2006; Nishimoto et al., 2007). In particular, tocilizumab, a monoclonal antibody against the IL-6 receptor, was found to have a positive effect on disease symptoms and to decrease the levels of markers of bone and cartilage degeneration in patients with RA (Garnero et al., 2010; Hashimoto et al., 2011).

Despite the clear degenerative effect of OSM at high levels, its mode of action in osteoarthritis seems to be somewhat different. Levels of OSM, but also of TNF $\alpha$ and IL-1 are low in OA synovial fluid (Vignon et al., 1993). Moreover, at the levels found in OA synovial fluid, OSM does not induce cartilage breakdown, which is in line with the observation that inhibition of the OSM present in OA synovial fluid does not inhibit GAG release. In contrast, the increased production and deposition of extracellular matrix found upon inhibition of OSM activity rather suggests an inhibitory effect of OSM on an anabolic factor(s) in the synovial fluid. In other studies, the precise role and effect of OSM on extracellular matrix production should be further investigated.

As this is an artificial in vitro model with only cartilage explants, we cannot exclude that the culture method (e.g. culture medium with high concentration insulin, no bone or synovial tissue present) may have partly masked the effect of inhibiting OSM. Future in vivo experiments will show if inhibiting OSM could stop OA degeneration in a more challenging and less controlled environment.

It should be borne in mind that in almost $70 \%$ of the OA synovial fluid samples OSM was undetectable, and hence its role may be limited to those patients in which OSM is produced. The presence of OSM in some patients may suggest different (stages of) pathology. We have recently shown that OSM clusters with several other cytokines, such as IL-1 $\beta$, IL-8 and IFN $\gamma$, suggesting it is part of a common pathway (Beekhuizen et al., 2013), which should be further investigated. We observed, however, no association of OSM production with other aspects of pathology, such as synovial inflammation. However, we did not have access to the patient data and did not obtain synovial tissue of all OA patients, so we cannot state with certainty that this association did not exist. Still, as inhibition of these low concentrations already resulted in such clear effects on cartilage repair, it cannot be excluded that very low, but undetectable OSM levels were present in all donors and would still have resulted in increased matrix production upon inhibition. Even if this would not hold true, a $30 \%$ reduction in OA disease morbidity would already have a huge impact on society in terms of disease burden. It is important to note that the synovial fluid could only be used at $25 \%$, due to its limited availability, suggesting that the enhancement of cartilage matrix production may have been even more pronounced with higher concentrations of synovial fluid.

\section{Conclusions}

This study shows that OSM plays a role in cartilage matrix turnover during osteoarthritis. By blocking OSM in the synovial fluid of OA patients, cartilage repair is improved in osteoarthritic cartilage. Supported by the lack of effect found for exogenously added OSM, these data indicate that OSM indirectly inhibits repair mechanisms in osteoarthritis. Moreover, the presence of receptors for OSM in both cartilage and synovial tissue suggests that blocking OSM could have an effect on multiple joint tissues and not just cartilage. The current study is one of the first that show that cartilage repair can be improved by altering the joint environment in osteoarthritis. 

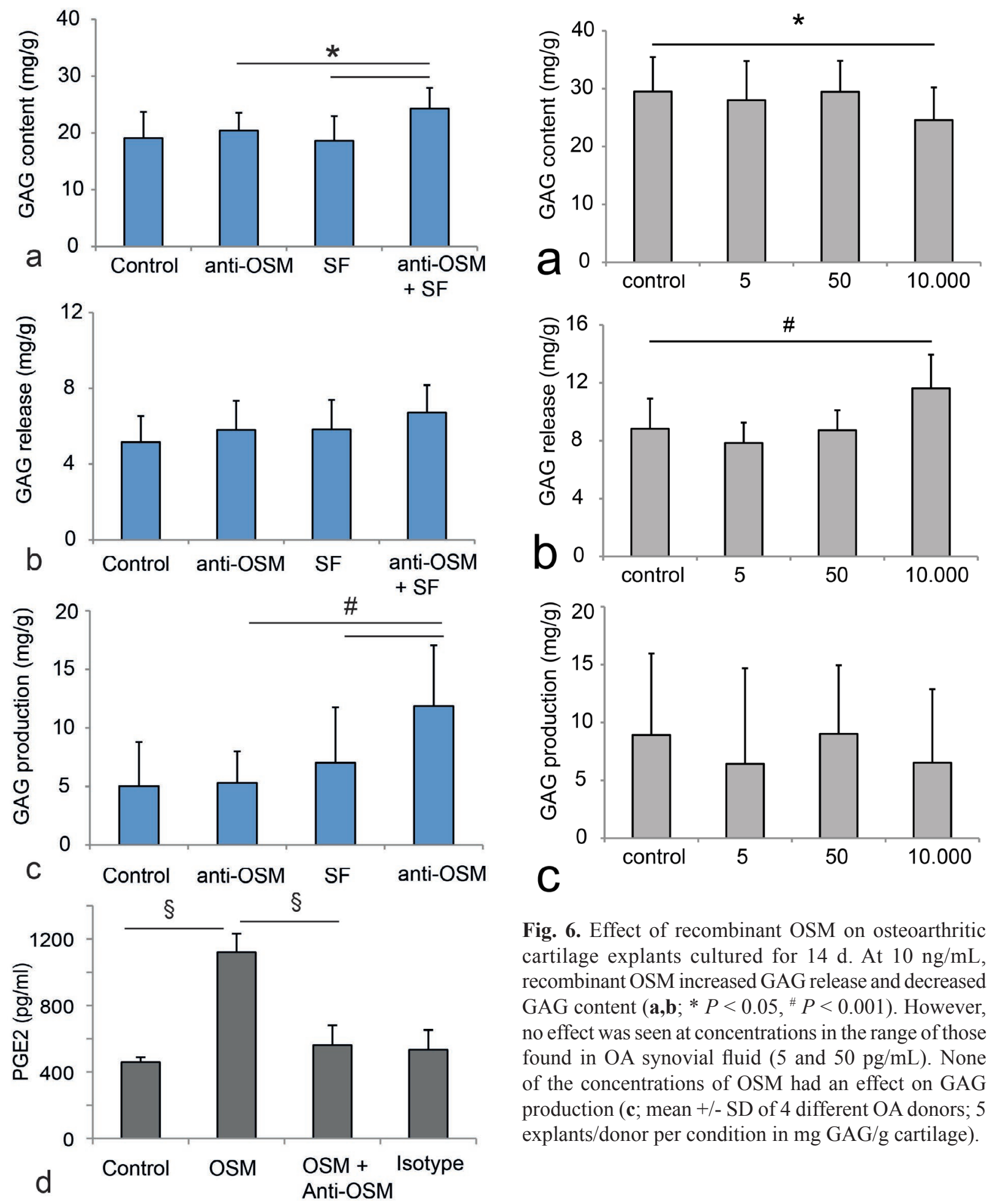

Fig. 6. Effect of recombinant OSM on osteoarthritic cartilage explants cultured for $14 \mathrm{~d}$. At $10 \mathrm{ng} / \mathrm{mL}$, recombinant OSM increased GAG release and decreased GAG content $\left(\mathbf{a}, \mathbf{b} ;{ }^{*} P<0.05,{ }^{*} P<0.001\right)$. However, no effect was seen at concentrations in the range of those found in OA synovial fluid ( 5 and $50 \mathrm{pg} / \mathrm{mL}$ ). None of the concentrations of OSM had an effect on GAG production (c; mean $+/$ - SD of 4 different OA donors; 5 explants/donor per condition in $\mathrm{mg} \mathrm{GAG/g}$ cartilage).

Fig. 5. Effect of blocking OSM in synovial fluid on osteoarthritic cartilage explants cultured for $14 \mathrm{~d}$. Blocking OSM in osteoarthritic synovial fluid increased GAG content in cartilage $(\mathbf{a} ; * P<0.03)$ and increased GAG production $\left(\mathbf{c} ;{ }^{\#} P<0.003\right)$, however, did not have an effect on GAG release (b). Addition of only synovial fluid did not have an effect on GAG content, release or production in osteoarthritic cartilage (mean $\pm \mathrm{SD}$ of 5 different OA donors; 5 explants per donor/condition in $\mathrm{mg}$ GAG/g cartilage). AntiOSM, at a concentration of $10 \mu \mathrm{g} / \mathrm{mL}$, completely decreased the production of PGE2 induced by $2 \mathrm{ng} / \mathrm{mL}$ of recombinant OSM by OA chondrocytes $(\mathbf{d} ; \S P<0.001$; mean $+/-\mathrm{SD}$ of 1 donor; $n=4$ per condition). 


\section{Acknowledgements}

This research forms part of the Project P2.02 OAcontrol of the research program of the BioMedical Materials institute, co-funded by the Dutch Ministry of Economic Affairs, Agriculture and Innovation. L.B. Creemers is funded by a research grant of the Dutch Arthritis Association. We wish to confirm that there are no known conflicts of interest associated with this publication and there has been no significant financial support for this work that could have influenced its outcome.

\section{References}

Allan EH, Hilton DJ, Brown MA, Evely RS, Yumita S, Metcalf D, Gough NM, Ng KW, Nicola NA, Martin TJ (1990) Osteoblasts display receptors for and responses to leukemia-inhibitory factor. J Cell Physiol 145: 110-119.

Barksby HE, Hui W, Wappler I, Peters HH, Milner JM, Richards CD, Cawston TE, Rowan AD (2006) Interleukin-1 in combination with oncostatin $\mathrm{M}$ upregulates multiple genes in chondrocytes: implications for cartilage destruction and repair. Arthritis Rheum 54: 540-550.

Beekhuizen M, Bastiaansen-Jenniskens YM, Koevoet W, Saris DB, Dhert WJ, Creemers LB, van Osch GJ (2011) Osteoarthritic synovial tissue inhibition of proteoglycan production in human osteoarthritic knee cartilage: establishment and characterization of a long-term cartilagesynovium coculture. Arthritis Rheum 63: 1918-1927.

Beekhuizen M, Gierman LM, van Spil WE, Van Osch GJ, Huizinga TW, Saris DB, Creemers LB, Zuurmond AM (2013) An explorative study comparing levels of soluble mediators in control and osteoarthritic synovial fluid. Osteoarthritis Cartilage 21: 918-922.

Catterall JB, Carrere S, Koshy PJ, Degnan BA, Shingleton WD, Brinckerhoff CE, Rutter J, Cawston TE, Rowan AD (2001) Synergistic induction of matrix metalloproteinase 1 by interleukin-1alpha and oncostatin $\mathrm{M}$ in human chondrocytes involves signal transducer and activator of transcription and activator protein 1 transcription factors via a novel mechanism. Arthritis Rheum 44: 2296-2310.

Cawston TE, Curry VA, Summers CA, Clark IM, Riley GP, Life PF, Spaull JR, Goldring MB, Koshy PJ, Rowan AD, Shingleton WD (1998) The role of oncostatin M in animal and human connective tissue collagen turnover and its localization within the rheumatoid joint. Arthritis Rheum 41: 1760-1771.

de Jager W, te Velthuis H, Prakken BJ, Kuis W, Rijkers GT (2003) Simultaneous detection of 15 human cytokines in a single sample of stimulated peripheral blood mononuclear cells. Clin Diagn Lab Immunol 10: 133-139.

de Jager W, Prakken BJ, Bijlsma JW, Kuis W, Rijkers GT (2005) Improved multiplex immunoassay performance in human plasma and synovial fluid following removal of interfering heterophilic antibodies. J Immunol Methods 300: 124-135.

Durigova M, Roughley PJ, Mort JS (2008a) Mechanism of proteoglycan aggregate degradation in cartilage stimulated with oncostatin M. Osteoarthritis Cartilage 16: 98-104.

Durigova M, Soucy P, Fushimi K, Nagase H, Mort JS, Roughley PJ (2008b) Characterization of an ADAMTS5-mediated cleavage site in aggrecan in OSM-stimulated bovine cartilage. Osteoarthritis Cartilage 16: 1245-1252.

Durigova M, Troeberg L, Nagase H, Roughley PJ, Mort JS (2011) Involvement of ADAMTS5 and hyaluronidase in aggrecan degradation and release from OSM-stimulated cartilage. Eur Cell Mater 21: 31-45.

Farndale RW, Buttle DJ, Barrett AJ (1986) Improved quantitation and discrimination of sulphated glycosaminoglycans by use of dimethylmethylene blue. Biochim Biophys Acta 883: 173-177.

Fearon U, Mullan R, Markham T, Connolly M, Sullivan S, Poole AR, FitzGerald O, Bresnihan B, Veale DJ (2006) Oncostatin M induces angiogenesis and cartilage degradation in rheumatoid arthritis synovial tissue and human cartilage cocultures. Arthritis Rheum 54: 31523162.

Felson DT (2006) Clinical practice. Osteoarthritis of the knee. N Engl J Med 354: 841-848.

Fernandes JC, Martel-Pelletier J, Pelletier JP (2002) The role of cytokines in osteoarthritis pathophysiology. Biorheology 39: 237-246.

Garnero P, Thompson E, Woodworth T, Smolen JS (2010) Rapid and sustained improvement in bone and cartilage turnover markers with the anti-interleukin-6 receptor inhibitor tocilizumab plus methotrexate in rheumatoid arthritis patients with an inadequate response to methotrexate: results from a substudy of the multicenter double-blind, placebo-controlled trial of tocilizumab in inadequate responders to methotrexate alone. Arthritis Rheum 62: 33-43.

Gearing DP, Comeau MR, Friend DJ, Gimpel SD, Thut CJ, McGourty J, Brasher KK, King JA, Gillis S, Mosley B, Ziegler SF, Cosman D (1992) The IL-6 signal transducer, gp130: an oncostatin M receptor and affinity converter for the LIF receptor. Science 255: 1434-1437.

Gilbert SJ, Blain EJ, Al-Sabah A, Zhang Y, Duance VC, Mason DJ (2012) Protein kinase R plays a pivotal role in oncostatin $\mathrm{M}$ and interleukin-1 signalling in bovine articular cartilage chondrocytes. Eur Cell Mater 23: 41-57.

Goldring SR, Goldring MB (2004) The role of cytokines in cartilage matrix degeneration in osteoarthritis. Clin Orthop Relat Res 427 Suppl: S27-36.

Goldring MB, Marcu KB (2009) Cartilage homeostasis in health and rheumatic diseases. Arthritis Res Ther 11: 224.

Halfter H, Friedrich M, Postert C, Ringelstein EB, Stogbauer F (1999) Activation of Jak-Stat and MAPK2 pathways by oncostatin $\mathrm{M}$ leads to growth inhibition of human glioma cells. Mol Cell Biol Res Commun 1: 109116.

Hashimoto J, Garnero P, van der Heijde D, Miyasaka N, Yamamoto K, Kawai S, Takeuchi T, Yoshikawa H, Nishimoto N (2011) Humanized anti-interleukin-6receptor antibody (tocilizumab) monotherapy is more effective in slowing radiographic progression in patients with rheumatoid arthritis at high baseline risk for structural damage evaluated with levels of biomarkers, radiography, 
and BMI: data from the SAMURAI study. Mod Rheumatol 21: $10-15$.

Hui W, Bell M, Carroll G (1997) Detection of oncostatin $M$ in synovial fluid from patients with rheumatoid arthritis. Ann Rheum Dis 56: 184-187.

Hui W, Rowan AD, Cawston T (2000) Transforming growth factor beta1 blocks the release of collagen fragments from boving nasal cartilage stimulated by oncostatin $\mathrm{M}$ in combination with IL-1alpha. Cytokine 12: $765-769$.

Hui W, Rowan AD, Cawston T (2001) Insulin-like growth factor 1 blocks collagen release and down regulates matrix metalloproteinase-1, $-3,-8$, and -13 mRNA expression in bovine nasal cartilage stimulated with oncostatin $\mathrm{M}$ in combination with interleukin 1alpha. Ann Rheum Dis 60: 254-261.

Hui W, Rowan AD, Richards CD, Cawston TE (2003) Oncostatin M in combination with tumor necrosis factor alpha induces cartilage damage and matrix metalloproteinase expression in vitro and in vivo. Arthritis Rheum 48: 3404-3418.

Hui W, Cawston TE, Richards CD, Rowan AD (2005) A model of inflammatory arthritis highlights a role for oncostatin $\mathrm{M}$ in pro-inflammatory cytokine-induced bone destruction via RANK/RANKL. Arthritis Res Ther 7: R57-64.

Maini RN, Taylor PC, Szechinski J, Pavelka K, Broll J, Balint G, Emery P, Raemen F, Petersen J, Smolen J, Thomson D, Kishimoto T (2006) Double-blind randomized controlled clinical trial of the interleukin- 6 receptor antagonist, tocilizumab, in European patients with rheumatoid arthritis who had an incomplete response to methotrexate. Arthritis Rheum 54: 2817-2829.

Manicourt DH, Poilvache P, Van Egeren A, Devogelaer JP, Lenz ME, Thonar EJ (2000) Synovial fluid levels of tumor necrosis factor alpha and oncostatin $\mathrm{M}$ correlate with levels of markers of the degradation of crosslinked collagen and cartilage aggrecan in rheumatoid arthritis but not in osteoarthritis. Arthritis Rheum 43: 281-288.

Martel-Pelletier J, Alaaeddine N, Pelletier JP (1999) Cytokines and their role in the pathophysiology of osteoarthritis. Front Biosci 4: D694-703.

Martel-Pelletier J, Boileau C, Pelletier JP, Roughley PJ (2008) Cartilage in normal and osteoarthritis conditions. Best Pract Res Clin Rheumatol 22: 351-384.

Mastbergen SC, Bijlsma JW, Lafeber FP (2005) Selective COX-2 inhibition is favorable to human early and late-stage osteoarthritic cartilage: a human in vitro study. Osteoarthritis Cartilage 13: 519-526.

Miyajima A, Kinoshita T, Tanaka M, Kamiya A, Mukouyama Y, Hara T (2000) Role of oncostatin M in hematopoiesis and liver development. Cytokine Growth Factor Rev 11: 177-183.

Mosley B, De Imus C, Friend D, Boiani N, Thoma B, Park LS, Cosman D (1996) Dual oncostatin M (OSM) receptors. Cloning and characterization of an alternative signaling subunit conferring OSM-specific receptor activation. J Biol Chem 271: 32635-32643.

Nishimoto N, Hashimoto J, Miyasaka N, Yamamoto K, Kawai S, Takeuchi T, Murata N, van der Heijde D, Kishimoto T (2007) Study of active controlled monotherapy used for rheumatoid arthritis, an IL-6 inhibitor (SAMURAI): evidence of clinical and radiographic benefit from an $x$ ray reader-blinded randomised controlled trial of tocilizumab. Ann Rheum Dis 66: 1162-1167.

Nowell MA, Richards PJ, Fielding CA, Ognjanovic S, Topley N, Williams AS, Bryant-Greenwood G, Jones SA (2006) Regulation of pre-B cell colony-enhancing factor by STAT-3-dependent interleukin- 6 trans-signaling: implications in the pathogenesis of rheumatoid arthritis. Arthritis Rheum 54: 2084-2095.

Okamoto H, Yamamura M, Morita Y, Harada S, Makino H, Ota Z (1997) The synovial expression and serum levels of interleukin-6, interleukin-11, leukemia inhibitory factor, and oncostatin $\mathrm{M}$ in rheumatoid arthritis. Arthritis Rheum 40: 1096-1105.

Plater-Zyberk C, Buckton J, Thompson S, Spaull J, Zanders E, Papworth J, Life PF (2001) Amelioration of arthritis in two murine models using antibodies to oncostatin M. Arthritis Rheum 44: 2697-2702.

Pritzker KP, Gay S, Jimenez SA, Ostergaard K, Pelletier JP, Revell PA, Salter D, van den Berg WB (2006) Osteoarthritis cartilage histopathology: grading and staging. Osteoarthritis Cartilage 14: 13-29.

Rosenberg L (1971) Chemical basis for the histological use of safranin $\mathrm{O}$ in the study of articular cartilage. J Bone Joint Surg Am 53: 69-82.

Rowan AD, Koshy PJ, Shingleton WD, Degnan BA, Heath JK, Vernallis AB, Spaull JR, Life PF, Hudson K, Cawston TE (2001) Synergistic effects of glycoprotein 130 binding cytokines in combination with interleukin-1 on cartilage collagen breakdown. Arthritis Rheum 44: 1620-1632.

Royuela M, Ricote M, Parsons MS, Garcia-Tunon I, Paniagua R, de Miguel MP (2004) Immunohistochemical analysis of the IL-6 family of cytokines and their receptors in benign, hyperplasic, and malignant human prostate. $\mathrm{J}$ Pathol 202: 41-49.

Rutgers M, Saris DBF, Auw Yang KG, Dhert WJA, Creemers LB (2009) Joint injury and osteoarthritis: soluble mediators in the course and treatment of cartilage pathology. Immunotherapy 1: 435-445.

Sims NA, Walsh NC (2010) GP130 cytokines and bone remodelling in health and disease. BMB Rep 43: 513-523.

Tanaka T, Umesaki N (2003) Oncostatin M inhibits decidualization of normal human endometrial stromal cells. Int J Mol Med 11: 627-630.

Tanaka M, Hirabayashi Y, Sekiguchi T, Inoue T, Katsuki M, Miyajima A (2003) Targeted disruption of oncostatin $\mathrm{M}$ receptor results in altered hematopoiesis. Blood 102: 3154-3162.

Thoma B, Bird TA, Friend DJ, Gearing DP, Dower SK (1994) Oncostatin M and leukemia inhibitory factor trigger overlapping and different signals through partially shared receptor complexes. J Biol Chem 269: 6215-6222.

van Diest PJ (2002) No consent should be needed for using leftover body material for scientific purposes. For. BMJ 325: 648-651.

Vignon E, Balblanc JC, Mathieu P, Louisot P, Richard M (1993) Metalloprotease activity, phospholipase A2 activity and cytokine concentration in osteoarthritis synovial fluids. Osteoarthritis Cartilage 1: 115-120. 
Walker EC, McGregor NE, Poulton IJ, Solano M, Pompolo S, Fernandes TJ, Constable MJ, Nicholson GC, Zhang JG, Nicola NA, Gillespie MT, Martin TJ, Sims NA (2010) Oncostatin M promotes bone formation independently of resorption when signaling through leukemia inhibitory factor receptor in mice. J Clin Invest 120: $582-592$.

Znoyko I, Sohara N, Spicer SS, Trojanowska M, Reuben A (2005) Expression of oncostatin $M$ and its receptors in normal and cirrhotic human liver. J Hepatol 43: $893-900$

\section{Discussion with Reviewers}

Reviewer I: How does a positive effect on GAG production and release in vitro equate to a positive effect on cartilage regeneration in vivo? Surely, cartilage regeneration depends on more than GAG production.

Authors: Our focus has been on GAG turnover as one of the major outcome parameters of cartilage repair, a commonly used readout parameter in cartilage research. We agree with the reviewer that there is more to cartilage repair than only GAG production. Collagen II production would also be very informative, but turnover of collagen is slow and hence differences in collagen content will be difficult to detect in biochemical analysis in such a short culture period. Whether any effect in vitro can be reproduced in vivo is always a matter of debate and we certainly agree that given the promising results in vitro, it would be interesting as a next step to investigate the effect of intra-articular anti-OSM in an experimental model of osteoarthritis in vivo.

Reviewer I: Does OA cartilage regenerate or repair?

Authors: The reviewer raises an important issue that possibly should also be raised in the cartilage community in general. According to the Biology online definition, regeneration is "The natural renewal of a structure, as of a lost tissue or part" and to the Oxford Dictionary "The formation of new animal or plant tissue". As cartilage tissue is present before start of the culturing of the explants (see Fig. 2), the correct term should indeed be repair of the osteoarthritic cartilage. Restoration of the articular surface in vivo would then involve both repair, i.e. of the existing cartilage, and regeneration, i.e. of the surfaces completely devoid of cartilage. Suboptimal or scar tissue could be considered as repair tissue as stated in the definition above, however scar tissue in the end is not functional. As the current study involves pre-existent OA cartilage, we refer to our findings as "repair". 